Synthesis, part of a Special Feature on Applied Research for Enhancing Human Well-Being and Environmental Stewardship: Using Complexity Thinking in Southern Africa

\title{
Exploring the implications of critical complexity for the study of social- ecological systems.
}

\author{
$\underline{\text { Michelle Audouin }}^{1}, \underline{\text { Rika Preiser }}^{2}$, Shanna Nienaber $^{1}$, Linda Downsborough $^{3}$, Johann Lanz and Sydney Mavengahama ${ }^{4}$
}

\begin{abstract}
The complexity of social-ecological systems is well recognized (Berkes et al. 2003, Norberg and Cumming 2008). However, in the study of such systems, it is often the uncertainty that results from nonlinear interactions that forms the focus of discussion. Here, the normative implications of complexity for our knowledge of such systems are emphasised, by drawing largely on the work of Cilliers $(1998,2005 a)$, who introduced the term "critical complexity." This perspective on complexity is distinct in bringing the value-based choices that frame our knowledge generation strategies to the fore. It is from this view that we investigate the implications of complexity for social-ecological systems research. Based on these implications, we propose a set of five key questions to guide the incorporation of insights from critical complexity into such research. We end with a brief application of the questions proposed to the National Freshwater Ecosystem Priority Areas (NFEPA) project in South Africa, to illustrate their potential use in the context of resource management.
\end{abstract}

Key Words: critical complexity; freshwater conservation; knowledge types; social-ecological systems

\section{INTRODUCTION}

The complex nature of social-ecological systems is frequently recognized (Berkes et al. 2003, Norberg and Cumming 2008). However, there are many different interpretations of what constitutes the notion of complexity (Chu et al. 2003, Urry 2005). In the study of social-ecological systems, it is often the uncertainty that results from nonlinear interactions that forms the focus of attention. Here, the normative, that is, value-based implications of complexity for our knowledge of socialecological systems, is brought to the fore. We draw largely on the work of Cilliers $(1998,2005 a)$, whose interpretation of complexity is distinct in its explicit recognition of the normative choices that frame our knowledge-generation strategies.

The debate on complexity is typically situated in opposition to strong reductionist approaches to scientific study. However, Cilliers argues that although we cannot avoid reduction in our pursuit to understand social-ecological systems, we can turn our attention to the framing strategies that we employ when undertaking such reduction. This leads to a more selfreflexive, post-reductionist position (Preiser 2012).

Here, we investigate the implications of complexity for the study of social-ecological systems from this unique perspective. These implications are discussed in terms of two broad categories, namely, (1) those that relate to engaging with different knowledge systems and types; and (2) the normative context governing our research scope. Based on this discussion, we propose five key questions to guide the design of research processes in a way that recognizes critical complexity. These questions can be used as a conceptual tool in explicitly defining the research frame when studying socialecological systems. To illustrate the potential use of these questions, we have applied them to the National Freshwater Ecosystem Priority Areas (NFEPA) project undertaken in South Africa. The NFEPA project demonstrates how elements of critical complexity may be incorporated into the formulation of research and intervention strategies pertaining to social-ecological systems.

\section{CRITICAL COMPLEXITY: THEORETICAL EXPLORATION}

The notion of complexity reveals the limitations of traditional scientific methods that are founded on a reductionist paradigm (Berkes et al. 2003, Burns et al. 2006, Kauffman 2008). Inherent in this paradigm are assumptions of determinism, objectivism, universalism, and positivism (Heylighen et al. 2007). These assumptions find expression in strategies of analysis that isolate system components in the study process. Through a complexity lens, the dynamic relations among such components are emphasized, including the relation between the observer and that which is being observed (Cilliers 1998, Holling 2001). This leads to an acknowledgement of system characteristics such as "emergence" and "nonlinearity." Such characteristics are often used in the critique of reductionist strategies from a complexity perspective (Goldstein 1999, Heylighen et al. 2007, Mazzocchi 2008, Mitchell 2009). Therefore, the study of complexity introduces a shift in our epistemological practices, incorporating a self-reflective understanding of the limitations of the reductionist paradigm. However, theories of complexity are by no means original in their attempt to expose the limitations of reductionist practices (Preiser 2012). Philosophers of science, such as Popper

${ }^{1}$ Council for Scientific and Industrial Research, ${ }^{2}$ Centre for Studies in Complexity, Stellenbosch University, ${ }^{3}$ Monash University, ${ }^{4}$ Department of Agriculture, University of Zululand 
(1963), Feyerabend (1975) and Kuhn (1996), are well known for their arguments against false claims of objectivity and scientific autonomy.

Nevertheless, from a complexity perspective, the challenge to reductionism remains ambiguous. Typically, this challenge falls into one of two traps (Preiser 2012). Either it is grounded in an entirely anti-reductionist position that promotes a systems view of radical openness, leading to a relativist kind of holism in which the distinction between the system and its environment is lost; or it insists that all complexity can be understood through measurement and computational simulation (Holland 1995, Morin 2008). Morin (2008:33) critiques the former as a reaction to reductionism, which insists on a kind of holism that is "....never anything more than a plastic bag enveloping whatever it found any way it could, and...the more the totality becomes full, the emptier it becomes." Such holism is a strong form of constructivism that negates the need for a reliable ontology, as reality is described in terms of our knowledge thereof (Preiser 2012). Despite the strong opposition to reductionism inherent in this view, it is precisely such a strategy that is employed in reducing all ontology to epistemology (Preiser 2012). In contrast, those complexity theorists who assert that all complexity can be conceptualized and measured in some way adopt a simplifying approach that does not recognize the intangible nature of many emergent properties, for example, a sense of place of a particular area. From this perspective, emergence is a matter of finding the right rules and laws to define the extent of complexity at hand. The idea that all complexity can be formalized, for example, by expression in fractals and power laws, remains largely unquestioned.

These conflicting positions reveal the difficulties in resolving the problem of reductionism in unambiguous terms. Indeed, it is arguable that this problem is the central dilemma in the study of complexity. Cilliers (2005b:261) articulates this dilemma as an inescapable "performative tension" within complexity. This performative tension results from the fact that a rigorous understanding of complexity is one that denies both total holism and total reductionism simultaneously; while still acknowledging that any description of a complex system necessarily performs some reduction of reality (Cilliers 2005b).

Therefore, we do not consider a complexity perspective as being in opposition to reductionist research strategies, but rather as both transcending and including such strategies. Here, the study of complex phenomena is at best a postreductionist effort that is necessarily a critical position (Preiser 2012). This insight is central to what Preiser and Cilliers (2010) term "critical complexity." Critical complexity follows the logic of reductionism, with a simultaneous awareness of the choices made in reducing the system. Such a self-reflexive kind of reductionism forms the basis of a self-critical understanding of complexity (Preiser 2012). It has the potential to disarm the animosities formed by opposing paradigms, for example, reductionism versus holism, without uniting them into a grand unifying truth.

The main implication of critical complexity for scientific practice is that it compels the scientist to acknowledge the need for reduction, while making the strategies for such reductionism transparent. This approach is contrary to the logical positivist position of classical Newtonian methods that largely disregard the implications of reductionist practices (Preiser 2012). Framed as a kind of "epistemological rethink" a post-reductionist position necessitates a "...paradigm shift from the Newtonian model that has dominated science, to an appraisal of complexity that includes both holism and reductionism" (Mazzocchi 2008:13).

By moving beyond the reductionist/holist schism, the logic of critical complexity does not merely react against the Newtonian paradigm, but includes an acknowledgement that, under certain conditions, this framework works perfectly well in facilitating understanding (Preiser 2012).

In summary, the post-reductionist position, that is, critical complexity, has significant implications for the way in which we understand knowledge generation when studying complex systems. Perhaps most fundamental is the normative, that is, value-based, turn that this position introduces to complexity theory (Preiser and Cilliers 2010, Woermann and Cilliers 2012). Below, we draw primarily on the work of Cilliers to elucidate this normative turn.

\section{IMPLICATIONS OF CRITICAL COMPLEXITY FOR THE STUDY OF SOCIAL-ECOLOGICAL SYSTEMS}

Cilliers' (2001) discussion of boundaries is particularly useful for understanding the normative turn in complexity and its implications for the study of social-ecological systems. Here, the notion of boundaries refers broadly to the framing practices that we employ in studying such systems. A critical reflection on the nature of these framing practices reveals that they undermine the reductionist paradigm in several ways (Ulanowicz 2009). Reductionist assumptions such as objectivism, determinism, universalism, and positivism presume that boundaries are value-free and fixed entities, leaving the subject-object divide uncontested. These assumptions also presume that delineating the object under study is fairly unproblematic.

However, reflecting on the notion of boundaries, Cilliers $(1998,2001)$ points out that because complex systems are open and comprise elements that are interconnected, the distinction between the system under study and its environment is not predetermined. If we wish to gain a comprehensive understanding of such systems, we theoretically need to understand all of their interactions with the environment. As this environment, in turn, interacts with many other systems 
through nonlinear relationships, we find ourselves in the position of trying to understand an impossibly large number of elements and their interconnections (Cilliers 1998, 2001). Therefore, to enable some understanding of the system, a responsibility lies with the research team to determine the extent of the system to be studied. This is achieved through setting boundaries. Therefore, such boundaries, whether conceptual, spatial, or temporal, for example, are essential as they enable the generation of knowledge. There are two main implications to being aware of framing practices such as boundary setting.

First, we reduce the complexity of the system by leaving out certain elements, and it is not possible to identify all that has been excluded (Cilliers 2001). Both those excluded elements that we are aware of, and those that we are not, interact with the system in a nonlinear way, meaning that small causes can have large effects on the system under study and vice versa. The level of uncertainty that this raises in our knowledge of complex systems is then compounded by the dynamic nature of such systems, which develop and change over time (Cilliers $2005 b$ ). This uncertainty inherent in the study of socialecological systems is well recognized, predominantly as it relates to nonlinear interactions (Holling 2001, Berkes et al. 2003, Gunderson 2003, Norberg and Cumming 2008). Indeed, Berkes et al. (2003:8) suggest the need for a "new kind of resource and environmental management science" that is critical of assumptions of control and prediction.

However, a second implication of the need to draw boundaries in the study of social-ecological systems is that such boundary definition cannot be made entirely objectively, but involves choices that are essentially value-based (Heylighen et al. 2007). Critical complexity highlights this aspect. Through the lens of critical complexity, it is apparent that our knowledge is dependent on these practices. These can be described in terms of two broad categories, namely (1) those that relate to the knowledge types and forms that we employ, and (2) the normative context governing our research scope. The latter relates not only to spatial aspects, but also to factors such as temporal dimensions, the issues to be included in the study, the data to be examined, and the stakeholders to be engaged (Resilience Alliance 2010). The implications of critical complexity for the study of social-ecological systems are discussed below in terms of these two categories of researchframing practices, that is, research boundaries.

\section{Engaging with different disciplines, knowledge types and knowledge forms}

The study of complexity poses a challenge to traditional assumptions of complete scientific objectivity (Prigogine 1997) and exposes the limitations of formal knowledgegenerating strategies that are based on this assumption. An awareness of the interpretive and, therefore, contextual elements of our knowledge challenges us to consider different knowledge types when studying social-ecological systems. The normative aspect of knowledge lies, inter alia, in its interpretive nature that distinguishes data from such knowledge. As Cilliers (2005a:609) argues, "There are facts that exist independently of the observer of those facts, but the facts do not have their meaning written on their faces. Meaning only comes to be in the process of interaction. Knowledge is interpreted data." Therefore, critical complexity highlights the fact that all knowledge of complex systems is the result of interpretation, and is associated with contextual factors such as the boundaries of the study, research methods chosen, and sources of knowledge included.

Therefore, understanding complex social-ecological systems requires engagement, not only with a range of disciplines, but also with various knowledge types and forms (Berkes et al. 2003, Burns and Weaver 2008). The normative dimension of our knowledge of such systems means that this engagement is needed, not only in generating an understanding of the system itself, but also in choosing — and making explicit—-the context/framework in which such knowledge is generated.

Both of these interrelated tasks require a transdisciplinary approach that includes empirical, pragmatic, and normative or value-based knowledge (Max-Neef 2005, Burns et al. 2006). Put simply, Max-Neef (2005) explains that transdisciplinary research addresses several questions using a range of skills and knowledge types (Table 1).

Table 1. Skills and knowledge types included in transdisciplinary research (Max-Neef 2005).

\begin{tabular}{lll}
\hline \hline Key questions & $\begin{array}{l}\text { Examples of skills } \\
\text { needed }\end{array}$ & Type of knowledge \\
\hline What exists? & $\begin{array}{l}\text { Geology, physics, } \\
\text { sociology, ecology, } \\
\text { chemistry, economics }\end{array}$ & Empirical \\
What are we capable of & $\begin{array}{l}\text { Engineering, agriculture } \\
\text { forestry, commerce, } \\
\text { doing? }\end{array}$ & Pragmatic \\
What do we want to do? & $\begin{array}{l}\text { Planning, politics, law, } \\
\text { design } \\
\text { Values, philosophy, }\end{array}$ & $\begin{array}{l}\text { Normative/value- } \\
\text { based } \\
\text { Normative/value- } \\
\text { based }\end{array}$ \\
\hline $\begin{array}{l}\text { What ought we to be } \\
\text { doing? }\end{array}$ & & \\
\hline
\end{tabular}

When defining the normative (or value-based) context for research on social-ecological systems, for example, answers to questions such as "What exists?" and "What are we capable of doing?" are important. This knowledge may occur in any one of the following forms, or a mixture between them (Fabricius et al. 2006):

1. Explicit-formal: Knowledge that is in written form (explicit) and that has passed through a set of universally accepted rules (formal) that qualify it for use; for example, "scientific" knowledge; 
2. Explicit-informal: Knowledge that is in written form (explicit), but is subject to local rules of validity that are context-specific (informal);

3. Tacit-formal: Knowledge that is not documented, but held in people's memories and developed according to a set of universally accepted rules; for example, knowledge of scientists that is not codified; and

4. Tacit-informal: Knowledge contained in local memory and traditions that is usually transferred orally.

However, answering questions such as "What do we want to do?" and "What ought we to be doing?" requires not only empirical information, but also value-based knowledge, that takes us outside the realm of purely objective research into the domain of people's felt experiences, opinions, and cultural beliefs, as well as into the political sphere. Researchers of social-ecological systems often find themselves in the normative domain when facilitating the definition of local sustainability goals and objectives (Audouin and de Wet 2012). Again, this knowledge can occur in any one of the forms listed in Fabricius et al.'s (2006) typology. However, as opinions and values are highly subjective, they are most likely to fall into the categories of explicit-informal or tacit-informal knowledge.

When investigating the specific properties and characteristics of social-ecological systems, and recognizing that this investigation is contingent on the research framework within which the researchers are working, it is again important to engage with a range of disciplines and knowledge types and forms (Berkes et al. 2003). This is because, inter alia, the logic of complexity highlights the fact that the properties of socialecological systems emerge out of the interactions among the various elements of the system, rather than the characteristics of any one element in particular (Cilliers 2000, Holling 2001). Therefore, the social aspects of the system cannot be studied separately from the ecological ones. In addition, according to Wilber (2001), such systems possess both "interior" and "exterior" aspects that need to be understood (Audouin and Hattingh 2008). Examples of "interior" aspects include values, cultural beliefs, and power relations, whereas examples of "exterior" aspects are ecological and geological structures, population numbers and land-use patterns. To demonstrate further, a description of institutional structures and the issues that they are required to address concerns the "external" aspects of this issue, whereas the power relations among various departments and the effectiveness/quality with which mandates are fulfilled are more "internal" factors that arguably don't receive the same amount of attention when studying social-ecological systems. Generally, the study of "external" factors relies more on empirical, explicit, and formal knowledge, whereas that of "interior" aspects includes a significant amount of normative, tacit, and informal knowledge. Indigenous and traditional knowledge is a rich source of such tacit and informal knowledge; however, Kendrick (2003:263) argues that: "There is a relatively unexplored role for indigenous narratives within mainstream resource management systems."

Engagement with different knowledge types and forms needs to occur in ways that facilitate interactions among researchers from different disciplinary backgrounds, as well as among researchers and stakeholders that should be involved in answering the questions related to the "interior aspects of the system" that concern what we "want to do" and what we "ought to do." For example, it is suggested that, at the outset of a research process, some initial concept of the main elements of the system and the relationships between these-in relation to the problem or issue being studied-is formed (Walker et al. 2002, Will 2008, Audouin 2009). As a simple example, the links within a particular area between economic growth, the demand for residential development, the consequent clearing of vegetation, increases in erosion, and resultant decreases in land and water quality, may be sketched out through a process of interaction among disciplinary specialists and stakeholders. This facilitates a greater degree of understanding between these two groups of the linkages between their different knowledge spheres (Audouin 2009, Audouin and de Wet 2010a). Such conceptualizations can be supported by various communication techniques, such as causal-loop diagrams, mind mapping, and spatial overlays (Audouin and de Wet $2010 b$ ). However, it is important to include qualitative and narrative descriptions of issues of "interior aspects" such as values and power relations that are not easily represented through diagrams and maps (Audouin and de Wet 2010b).

\section{Bringing the normative aspects of the research scope to the fore}

A second type of framing practice that has normative implications for our knowledge of social-ecological systems is the choices we make in determining the scope of research studies. In determining this scope, there will always be decisions that are made which cannot be backed up objectively or scientifically (Heylighen et al. 2007). For example, determining the spatial extent of a study is typically influenced by a mix of tangible, "more objective" factors such as physical features such as catchment boundaries, as well as more "subjective" choices, for example, the range of issues to be addressed as identified by stakeholders, political imperatives or the strategic priorities of the research institutes involved (Audouin and de Wet 2010a). Selecting the scales at which the study is undertaken is part of such boundary definition. Although this selection should be guided by a range of social, economic and ecological factors (Resilience Alliance 2010), it involves an important strategic choice. As Berkes et al. (2003:8) state, the multiplicity of scales that exist means that there is "...no one "correct" and all-encompassing perspective on a system. One can choose to study a particular level of biodiversity conservation; but the perspective from that 
particular level will be different from the perspective from another."

Determining the objective of the social-ecological system research is also part of defining its scope. In most instances, this objective relates to promoting the sustainability of such systems. However, sustainability itself is as much a valuebased concept as it is a traditionally scientific one (Audouin and De Wet 2012). This concept is strongly influenced by the world view of those defining it, particularly as this pertains to the human-nature relationship. This relationship is not only a vital part of the social system being studied (Berkes et al. 2003), but also of what is defined at the "desired state" of the coupled social-ecological system, and, therefore the objective of much research undertaken in this domain. As Berkes et al. (2003:8) emphasize, “...the choice of management direction itself is a qualitative decision." The value-based choices that inform the definition of sustainability and, therefore, the management direction, are consequently an integral part of the normative framework within which the scientific studies of social-ecological systems are undertaken.

Therefore, a critical complexity lens reveals that it is not possible to first identify the social-ecological system, as if the researcher and the other aspects related to the context of the study were separate from this description, and then derive knowledge of that system (Cilliers 2005a). In many respects, this impossibility was recognized at the landmark Friibergh Workshop on Sustainability Science (2000:1), in the statement that: "Additional complications arise from the recognition that humans cannot stand outside the nature-society system." This point increases the importance of making the research-framing strategy explicit when developing an understanding of the social-ecological system (Audouin 2009, Preiser 2012). Making the research-framing strategy explicit enables others to understand the study and its outcomes better. In recognizing that this strategy strongly influences the nature of the knowledge generated, the importance of involving key political and implementing agencies becomes apparent. By engaging stakeholders in defining the research frame, the knowledge generated becomes more relevant to those that are responsible for its use in various government and other decision-making processes. As stated by Kates et al. (2001:641), in the context of sustainability science: “...in a world put at risk by the unintended consequences of scientific progress, participatory procedures involving scientists, stakeholders, advocates, active citizens, and users of knowledge are critically needed." The relatively recent debate about transdisciplinarity echoes this need for a participatory approach to the generation of research problems (Pohl and Hadorn 2007).

In the process of exposing the research-framing practices that underlie any study of social-ecological systems, the normative aspects of the research scope, as well as the choices made regarding the use of different knowledge types, become apparent. To guide this process of exposing research boundaries, we propose that the following questions are considered when studying social-ecological systems:

1. Who should be involved in defining the purpose of the study, the problem to be addressed, and the skills to be included?

2. What values underpin the goals and objectives of the study?

3. What assumptions are made in defining the various spatial, temporal, and substantive (i.e., issues to be addressed) boundaries of the study?

4. What knowledge types are important to include in the process of gaining an understanding of the socialecological system?

5. How can the research process, its goals, and outcomes, be aligned with the needs and values of those most likely to be affected by its recommendations?

Asking questions, such as the ones listed above, begins to delineate approaches to the study of social-ecological systems that incorporate insights from critical complexity, from those that are either unaware of their framing strategies or that leave these unquestioned. Therefore, this list of questions serves as a conceptual tool that can be used in the process of formulating such research framing strategies.

\section{DEFINING BOUNDARIES: BRIEF APPLICATION OF RESEARCH FRAMING QUESTIONS TO NFEPA}

In the sections above, we elucidated the theoretical importance of critical complexity. We then discussed the implications of this specific view for the study of social-ecological systems. Based on these implications, which relate to the inclusion of different knowledge types and to defining the scope of research, we have proposed a set of five questions. Use of these questions in social-ecological systems research promotes sensitivity to the theoretical implications of critical complexity. Below, a brief example is provided to illustrate the applicability of these framing questions to the field of conservation and resource management.

\section{Background}

We have chosen South Africa's National Freshwater Ecosystem Priority Areas project as an illustration because it aimed to take a transdisciplinary approach (J. L. Nel, personal communication) that, in turn, professes to engage with the complexity of research problems. The debate around transdisciplinarity is one of the most promising streams of thought and practice to implicitly incorporate many of the elements of critical complexity. For example, through a transdisciplinary lens, the need to engage with different knowledge types in understanding linked social-ecological 
systems is evident (Max-Neef 2005). Also, an understanding of the normative nature of our research framing practices is embedded in the transdisciplinary imperative for joint problem definition, in which stakeholders participate in formulating the research question to be addressed (Pohl and Hadorn 2007).

The overall aim of the NFEPA project was to identify national freshwater conservation areas and to explore institutional mechanisms for their implementation (Nel et al. 2011). This 4-year project (August 2007-May 2011) was led by the South African National Biodiversity Institute (SANBI) and the Council for Scientific and Industrial Research (CSIR). The project team included representatives from the Water Research Commission (WRC), the Department of Water and Environmental Affairs (DWEA), the World Wildlife Fund (WWF), South African National Parks (SAN Parks), the South African Institute for Aquatic Biodiversity (SAIAB) and the Department of Environmental Affairs (DEA).

The scientific outputs of the project comprise two main components, namely:

1. A series of map products, which spatially indicate the priority freshwater conservation areas, explaining why they have been selected. This mapping is based on a detailed technical Geographical Information System (GIS), in which variables such as freshwater biodiversity, threatened fish species, river ecosystem type classification, structure, and function are considered, as well as significant wetlands and wetland clusters.

2. An implementation manual to support end users of the scientific products, indicating how these products can ease their work load and support their existing responsibilities.

A third component relates to the post-project implementation of these products, by implementing agencies such as provincial agencies, catchment managers, and parks authorities, in their daily work. For example, the products can provide guidance in the formulation of provincial conservation plans and in the granting of water licenses. Extensive effort has been made to include end users in the research process, to generate awareness of the use and purpose of the products and to tailor the maps and supporting documentation to user needs. A conceptual diagram of these three components, as well as the aim of the project and the project team is provided in Fig. 1 .

The National Freshwater Ecosystem Priority Areas was organized around five main tasks (South African National Biodiversity Institute 2008), namely:

1. Project inception;

2. Spatial mapping of the national freshwater ecosystem priority areas;
3. The development of freshwater ecosystem management guidelines for each map category;

4. The description of how the map products should be used within different legal and institutional contexts; and

5. The compilation of an atlas of national freshwater ecosystems, an institutional uptake manual, a final project report, and related digital material.

In the sections that follow, the NFEPA project will be discussed specifically in terms of the key questions regarding the research framing strategies as detailed above.

\section{Who should be involved in defining the purpose of the study, the problem to be addressed, and the skills to be included?}

The prioritization of freshwater conservation areas in the NFEPA project was not merely viewed as a traditionally technical task, but also a sociopolitical one. This is reflected in its aim, not only to identify such freshwater areas, but also to explore the institutional mechanisms for their implementation (South African National Biodiversity Institute 2008). This choice to broaden the boundaries beyond technical mapping led to several implications, both for the structure of the project team and the research process itself.

The NFEPA team included a diverse range of disciplinary specialists, such as political scientists, social ecologists, aquatic scientists, ichthyologists, chemists, environmental managers, water resource planners, and geographic information specialists. From the initial stage of proposal generation, multiple partners were on the team, including scientists, representatives from implementing agencies such as the Department of Environmental Affairs, and bridging organizations such as the World Wildlife Fund (Nel et al. 2011). Importantly in terms of problem definition, key stakeholders were invited to an inception workshop in which several approaches to the research were discussed (Nel et al. 2011). The outcomes of this workshop were included in the final design of the research process.

However, in examining the genesis of the NFEPA project and the way in which the problem to be addressed was identified, one cannot view NFEPA in isolation. The broader legal and policy context in which the products were developed was made explicit by the project team, and it is out of this context that the need for NFEPA originally arose. In terms of the policy environment, NFEPA had its roots in the Cross-Sector Policy Objectives for Inland Water Conservation, for example (South African National Biodiversity Institute 2008), which were formulated through a collaborative process. This process included the national departments responsible for governing biodiversity, water, the environment, agriculture, and development planning, among others, as well as South African National Parks (SANParks; Roux et al. 2006). In this respect, the systemic nature of the project of freshwater conservation 
Fig. 1. A conceptual diagram showing the aim of the NFEPA project, the project team, and the different components of the work.

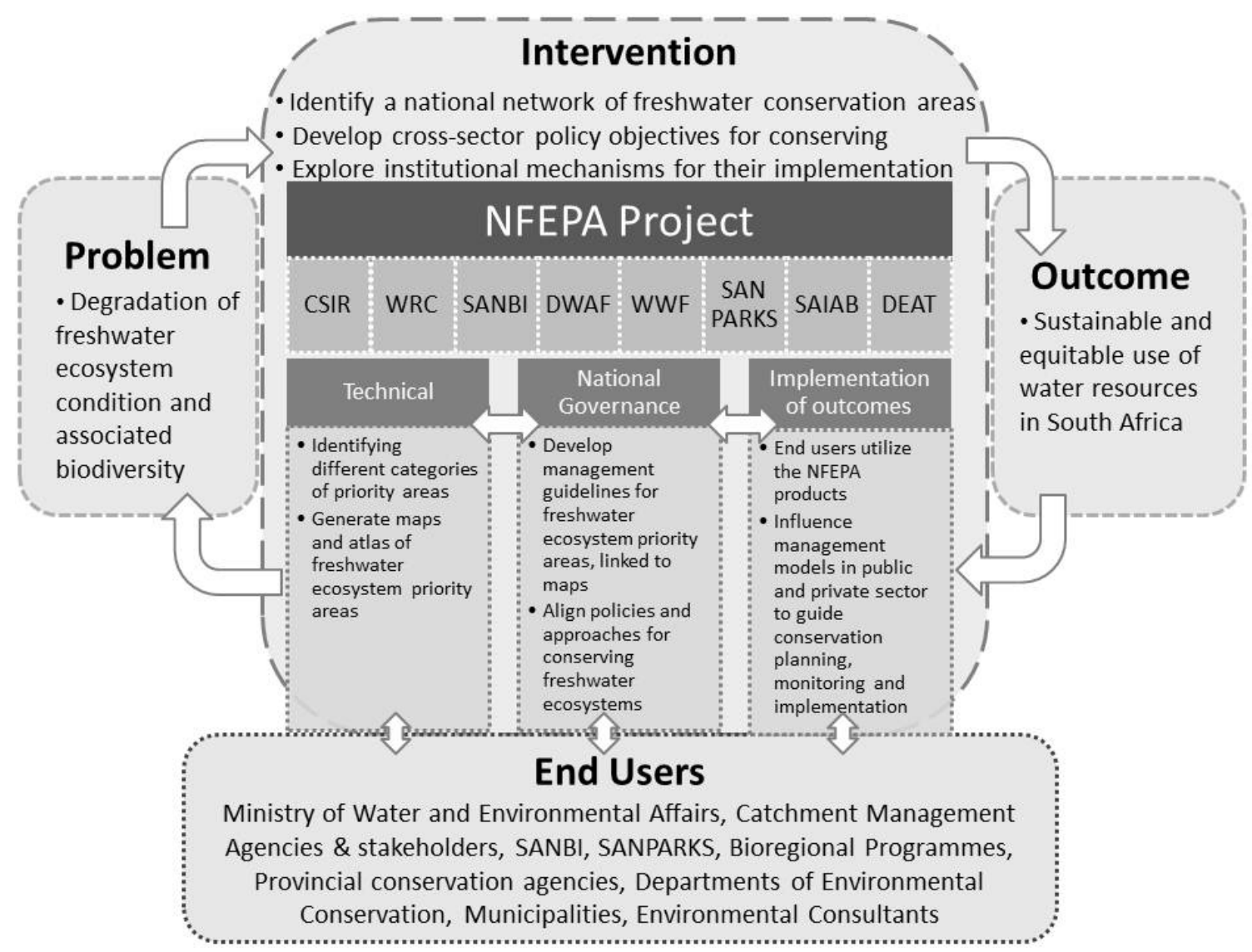

was recognized, as well as the need for cooperative action (Roux et al. 2006). Therefore, the problem addressed by NFEPA had its roots in participatory processes that occurred before the inception of the project itself.

\section{What values underpin the goals and objectives of the study?}

The values underpinning the study were strongly influenced by the policy and legislative context in which the study arose, as outlined above. More specifically, the Cross-Sector Policy Objectives for Inland Water Conservation included a shared goal "to conserve a sample of the full variety or diversity of inland water ecosystems that occur in South Africa, including all species as well as the habitats, landscapes, rivers and other water bodies in which they occur, together with the ecosystem processes responsible for generating and maintaining this diversity, for both present and future generations" (Roux et al. 2006:36). Therefore, it is within this normative context that the NFEPA project was undertaken.

From a legislative perspective, NFEPA was strongly rooted in the National Water Act (No. 36 of 1998) and the National
Environmental Management Biodiversity Act (No. 10 of 2004), for example. Both of these Acts were produced through extensive stakeholder engagement processes, and are generally considered to have wide legitimacy within South Africa. Therefore, NFEPA was viewed as a tool to aid in the realization of the values underlying these Acts. Although the project outputs do not include an analysis of this normative base, most likely because the need was to directly align with national legislation, a brief review of the development vs. environment perspective that is inherent in South Africa's legislation might have been useful. The project did go beyond this dichotomy in its explicit focus on linking ecological and social concerns, mainly where such social concerns related to the priorities and requirements of users of the scientific and technical information produced. This was a significant step forward that will greatly enhance the value of the products. However, in conceptualizing the freshwater priority areas as part of social-ecological systems, not only institutional and legislative aspects should be considered-but also other social elements such as adjacent land use, the characteristics of neighboring communities, as well as more intangible 
"interior" aspects such as community perceptions concerning freshwater ecosystems and the historical context of the system. However, some of these aspects may be most appropriately included at a finer scale of planning than the national level.

\section{What assumptions are made in defining the various spatial, temporal, and substantive (i.e., issues to be addressed) boundaries of the study?}

The boundaries of NFEPA were set at a national scale in response to the project's roots in national processes such as the Cross-Sector Policy Objectives for Inland Water Conservation (South African National Biodiversity Institute 2008). The NFEPA project also aimed to complement the first South African National Spatial Biodiversity Assessment (NSBA) undertaken in 2004, which related to terrestrial, river, marine, and estuarine ecosystems, but did not include freshwater ecosystems because of a lack of critical data (Nel et al. 2011). In addressing this knowledge gap, the scale and key focus-area of NFEPA was broadly determined. However, the outputs of the project were divided into those that related to the Water Management Area (WMA) level and those that related to the national level (South African National Biodiversity Institute 2008).

The NFEPA aim of implementing the five policy objectives outlined in the Cross-Sector Policy Objectives for Inland Water Conservation meant that the substantive scope of the project needed to be strongly informed by these objectives, which are as follows (South African National Biodiversity Institute 2008):

1. Set and entrench quantitative targets;

2. Plan for the representation of inland water biodiversity;

3. Maintain the processes which encourage the evolution and persistence of ecosystems;

4. Establish a network of inland water conservation areas; and

5. Enable effective implementation.

What knowledge types are important to include in the process of gaining an understanding of the socialecological system?

The NFEPA project included a range of different knowledge types and forms through its multidisciplinary and multiinstitutional project team. In addition, a stakeholder engagement process was undertaken that included workshops, meetings, one-on-one interviews, small group sessions, and quarterly newsletters (Nel et al. 2011). The workshops and meetings were attended by over 100 experts representing a range of private sector, government, and civil society organizations (Nel et al. 2011). With the focus on the end users of the project outputs, strong emphasis was placed on engaging with governmental departments tasked with addressing water and environmental issues, in the provincial and national spheres of government. This engagement brought scientific, technical, and experiential knowledge to the project.

There was less interaction with large water users (e.g., industry) and local communities for a number of reasons. Perhaps most importantly, NFEPA was undertaken on a national scale, and engaging with local users situated alongside freshwater systems right across the country was beyond the financial resources of the project. However, in acknowledging the importance of such participation, the team has emphasized the need for the refinement of the project outputs in the light of provincial and local contexts. Although efforts were made to contact them, there was also minimal interaction with political leaders, as access to these representatives was difficult to obtain.

Importantly, a diverse range of stakeholders were integral to a core element of the NFEPA process, i.e., identifying the criteria for the selection of the Freshwater Ecosystem Priority Areas (FEPAs). These criteria, which were very clearly presented, included aspects such as the existence of threatened fish, the representation of wetland clusters, and the existence of important migration routes such as fish corridors ( Nel et al. 2011). The inclusion of stakeholders in determining these aspects is commendable in its recognition of the need to include end-user values, preferences, and priorities in such research processes. This approach is essential to any transdisciplinary project.

Using Max-Neef's (2005) concept of transdisciplinarity as a guide, Table 2 provides examples how the NFEPA project answered, either directly or indirectly, the various questions associated with different types of knowledge.

How can the research process, its goals, and outcomes be aligned with the needs and values of those most likely to be affected by its recommendations?

The NFEPA team recognized that the project outputs would not be effectively used unless the values and priorities of the stakeholders involved in their implementation were included in the research process. The extension of the project, beyond technical data collection and spatial mapping, to include an understanding of the sociopolitical context in which the information was to be used, was an acknowledgement that science alone was not enough to ensure the protection of South Africa's freshwater ecosystems. Implementing agencies needed to be an integral part of the NFEPA process and obtaining a sense of support and ownership among these agencies was especially important.

Therefore, meetings were held with those responsible for the protection and use of freshwater across the country, including provincial agencies, parks authorities, and catchment managers, to provide these end users with a channel of communication and information about the project. The purpose was also to gain an understanding their specific needs 
Table 2. Transdisciplinarity and the NFEPA project.

\begin{tabular}{|c|c|c|c|}
\hline Key question & Answering the question in NFEPA & Type of knowledge & $\begin{array}{l}\text { Skills and other inputs in } \\
\text { answering the question }\end{array}$ \\
\hline What exists? & $\begin{array}{l}\text { Specialist information on, for example, wetland } \\
\text { delineations, wetland types, fish sanctuaries, free- } \\
\text { flowing rivers, groundwater recharge, and river } \\
\text { condition. Information on existing institutional } \\
\text { structures for conservation and strategic plans } \\
\text { also in place. }\end{array}$ & Empirical, scientific data & $\begin{array}{l}\text { Various disciplinary specialists on } \\
\text { the project team and end-users } \\
\text { within government departments } \\
\text { (e.g., ecologists, hydrologists). }\end{array}$ \\
\hline What are we capable of doing? & $\begin{array}{l}\text { The question was answered in terms of what we } \\
\text { are capable of doing in relation to water } \\
\text { conservation. The assumption was made that it is } \\
\text { impossible to conserve all the freshwater } \\
\text { resources in the country; however, some can be } \\
\text { preserved. Therefore, the project identified } \\
\text { priority freshwater ecosystem areas, advising on } \\
\text { which could be developed and which should be } \\
\text { conserved. }\end{array}$ & Pragmatic knowledge & $\begin{array}{l}\text { Various disciplinary specialists, } \\
\text { mainly from the natural sciences, } \\
\text { with advice from government } \\
\text { departments. }\end{array}$ \\
\hline What do we want to do? & $\begin{array}{l}\text { The project team wanted to more effectively } \\
\text { implement South Africa's existing legislation } \\
\text { related to freshwater conservation and assist end- } \\
\text { users in achieving this. }\end{array}$ & $\begin{array}{l}\text { Value-based/normative } \\
\text { knowledge }\end{array}$ & $\begin{array}{l}\text { Cross-Sector Policy Objectives for } \\
\text { Inland Water Conservation (Roux } \\
\text { et al. 2006), } \\
\text { existing legislation (e.g., } \\
\text { Biodiversity Act), } \\
\text { conversations with end-users, and } \\
\text { inputs from disciplinary } \\
\text { specialists. }\end{array}$ \\
\hline What ought we to do? & $\begin{array}{l}\text { At the heart of the project was a team that } \\
\text { strongly believed in the ethical value of balancing } \\
\text { development and the protection of ecosystems. } \\
\text { This value is also enshrined in South Africa's } \\
\text { Constitution and related legislation. }\end{array}$ & $\begin{array}{l}\text { Value-based/normative } \\
\text { knowledge }\end{array}$ & $\begin{array}{l}\text { Disciplinary specialists and end- } \\
\text { users within governmental } \\
\text { departments. }\end{array}$ \\
\hline
\end{tabular}

Note: Adapted from Max Neef (2005).

with regard to the use of the map products. These products were finalized in collaboration with stakeholders that participated, for example, in a national review workshop in July 2010 (Nel et al. 2011). The NFEPA project also included an extensive exploration of other similar programs, such as the River Health Program, and processes such as spatial biodiversity planning undertaken in South Africa, to learn from these how to effectively enable the use of NFEPA products (Nel et al. 2011). A key output of the project was an implementation manual that provides guidance, inter alia, on how the maps produced can be used in different legal and policy contexts ( $\mathrm{Nel}$ et al. 2011).

\section{CONCLUSION}

The self-reflective, normative turn of critical complexity, offers researchers and policy makers a means with which to understand and conceptualize the interrelated and dynamic nature of social-ecological systems in a unique way. Contrary to traditional scientific methods, which rely largely on principles of reduction and disjunction, the logic of critical complexity allows us to reflect critically upon the limitations of the knowledge generation and problem-solving interventions that are typically used to model and understand social-ecological systems. These limitations result from the need to construct boundaries when studying complex systems. Such boundary setting has, inter alia, the following consequences (Cilliers 2005b):

- All knowledge of complexity is valid in relation to a particular normative framework, and if any aspect of this framework changes, so must our knowledge of the system change;

- In drawing boundaries of the system, we always leave out certain elements and these interact with the socialecological system in a nonlinear way; 
- It is not possible to identify all the elements that have been left out in drawing the boundary and, therefore, to predict what their impact on the system being studied is and/or will be;

- The system has emergent properties, the behavior of which cannot be explained in terms of any single element, but is the result of the interactions among these; and

- The social-ecological system is dynamic, changing even as it is being studied and, sometimes, because of such studies.

The purpose of acknowledging the limitations of our ability to understand and frame social-ecological systems, and to predict their behavior, isn't to undermine current or past research, or to suggest that complex systems cannot be studied. Rather, as argued by Cilliers (2005b), the aim is to promote a "modest" approach to the communication of our research. This certainly does not mean that we have to take a weak position. We can still make clear and testable statements. "The fact that our knowledge is limited is not a disaster it is a condition for knowledge. Limits enable knowledge" (Cilliers 2005b:263). However, we have a responsibility to make our research framing strategies explicit. In this way, the framing process used in generating knowledge of social-ecological systems becomes more transparent. This opens the door to actively embracing plural, participatory, and interrelated strategies for sustainability that respond to the dynamic, flexible, interrelated, and often unpredictable nature of our world.

Engaging explicitly and consistently with a range of different disciplines, as well as different knowledge types and knowledge forms in this dynamic context, requires that the coordinator of the research has a very specific set of skills that includes:

1. Facilitation and the ability to elicit hidden assumptions and values behind stakeholder and specialist discussions;

2. An understanding of what tools are appropriate to use in different research contexts and the advantages and limitations of each;

3. Understanding what knowledge types and forms are most suitable to answer the range of research questions that arise;

4. An awareness of his/her own values that influence the research process and an ability to articulate these and debate them with the team;

5. An ability to listen to others without judgment that is based on a specific set of values, or on the knowledge form that $\mathrm{s} / \mathrm{he}$ is most comfortable engaging with; and

6. Flexibility and the skill to work within conditions of increased uncertainty, for example, being able to engage with stakeholders, with only a loose idea of the problem to be addressed, so that ideas can be debated and coformulated.

We presented the example of the NFEPA project to illustrate how an understanding of critical complexity may be applied. In our opinion, the NFEPA project demonstrated that, by including different kinds of knowledge (i.e., empirical, pragmatic and normative) and values (e.g., economic, aesthetic, spiritual, cultural, and recreational), a richer and more inclusive representation of the relationship between institutional and natural systems was obtained. Also, by actively encouraging the participation of end users in the research process, the products of NFEPA were particularly responsive to user needs. It is evident from the NFEPA project that, in a country like South Africa where society encompasses cultural, socioeconomic, and political diversity, the acknowledgement of complexity is not only a technical consideration when engaging in scientific and policy-making projects, but an ethical prerogative in effectively conserving and enhancing our social-ecological systems.

Responses to this article can be read online at: http://www.ecologyandsociety.org/issues/responses. $\mathrm{php} / 5434$

\section{Acknowledgments:}

The authors would like to acknowledge and thank Dr Jeanne $\mathrm{Nel}$ (CSIR) for her valuable comments on the case study included in this paper.

\section{LITERATURE CITED}

Audouin, M. A. 2009. Modernism, environmental assessment and the sustainability argument: moving towards a new approach to project-based decision-making in South Africa. Dissertation. University of Stellenbosch, Stellenbosch, South Africa.

Audouin, M. A., and J. Hattingh. 2008. Moving beyond modernism in environmental assessment and management. Pages 205-242 in M. Burns, and A. Weaver, editors. Exploring sustainability science: a southern African Perspective. Sun Press, Stellenbosch, South Africa.

Audouin, M. A., and B. de Wet. 2010a. Applied Integrative Sustainability Thinking (AIST): an introductory guide to incorporating sustainability thinking into environmental assessment and management. Council for Scientific and Industrial Research (CSIR), Pretoria, South Africa.

Audouin, M. A., and B. de Wet. 2010b. Conceptualising social-ecological systems in environmental assessment and 
management. CSIR Report No. 8765. CSIR, Stellenbosch, South Africa.

Audouin, M., and B. de Wet. 2012. Sustainability thinking in environmental assessment. Impact Assessment and Project Appraisal 30(4):264-274. DOI:10.1080/14615517.2012.742695. http://dx.doi.org/10.1080/14615517.2012.742695.

Berkes, F., J. Colding, and C. Folke. 2003. Navigating socialecological systems: building resilience for complexity and change. Cambridge University Press, Cambridge, UK. http:// dx.doi.org/10.1017/CBO9780511541957

Burns, M. E. R., Audouin, M. A., and A. Weaver A. 2006. Advancing sustainability science in South Africa. South African Journal of Science 102:379-384.

Burns M. E. R., and A. Weaver, editors. 2008. Exploring sustainability science: a southern African perspective. Sun Press, Stellenbosch, South Africa.

Chu, D., R. Strand, and R. Fjelland. 2003. Theories of complexity. Common denominators of complex systems. Complexity 8(3):19-30.

Cilliers, P. 1998. Complexity and postmodernism: understanding complex systems. Routledge, London, UK.

Cilliers, P. 2000. What can we learn from a theory of complexity? Emergence 2(1):23-33.

Cilliers, P. 2001. Boundaries, hierarchies and networks in complex systems. International Journal of Innovation Management 5(2):135-147.

Cilliers, P. 2005a. Knowledge, limits and boundaries. Futures 37:605-613.

Cilliers, P. 2005b. Complexity, deconstruction and relativism. Theory, Culture and Society 22(5):255-267.

Fabricius, C., R. Scholes, and J. Cundill. 2006. Mobilising knowledge of integrated ecosystem assessment. Pages 165182 in W. V. Reid, F. Berkes, T. J. Wilbanks, and D. Capisstrano, editors. Bridging Scales and Knowledge Systems. Island Press, Washington, D.C., USA.

Feyerabend, P. K. 1975. Against method. New Left Books, London, UK.

Friibergh Workshop on Sustainability Science. 2000. Sustainability science: statement of the Friibergh workshop on sustainability science. 11-14 October, Friibergh Manor, Örsundsbro, Sweden.

Goldstein, J. 1999. Emergence as a construct: history and issues. Emergence 1(1):49-72. http://dx.doi.org/10.1207/ $\underline{\mathrm{s} 15327000 \mathrm{em} 01014}$

Gunderson, L. H. 2003. Adaptive dancing: interactions between social resilience and ecological crises. Pages 33-52. in F. J. Berkes, C. Colding, and C. Folke, editors. Navigating social-ecological systems: building resilience for complexity and change. Cambridge University Press, Cambridge, UK. http://dx.doi.org/10.1017/CBO9780511541957.005

Heylighen, F., P. Cilliers, and C. Gershenson. 2007. Complexity and philosophy. Pages 117-134. in J. Bogg, and R. Geyer, editors. Complexity, Science and Society Radcliffe, Oxford, UK.

Holland, J. 1995. Hidden order. Helix, Reading, Massachusets, USA.

Holling, C. S. 2001. Understanding the complexity of economic, ecological and social systems. Ecosystems 4:390405. http://dx.doi.org/10.1007/s10021-001-0101-5

Kates, R. W., W. C. Clark, and R. Corell. 2001. Sustainability science. Science 292:641-642. http://dx.doi.org/10.1126/ science. 1059386

Kauffman, S. 2008. Reinventing the sacred. The science of complexity and the emergence of a natural divinity. Basic Books, New York, New York, USA.

Kendrick, A. 2003. Caribou co-management in northern Canada: fostering multiple ways of knowing. Pages 241-267 in F. J. Berkes, C.Colding, and C. Folke, editors. Navigating social-ecological systems: building resilience for complexity and change. Cambridge University Press, Cambridge, UK. http://dx.doi.org/10.1017/CBO9780511541957.015

Kuhn, T. 1996. The structure of scientific revolutions. University of Chicago Press, Chicago, Illinois, USA. http:// dx.doi.org/10.7208/chicago/9780226458144.001.0001

Max-Neef, M. A. 2005. Commentary: foundations of transdisciplinarity. Ecological Economics 53:5-16. http://dx. doi.org/10.1016/j.ecolecon.2005.01.014

Mazzocchi, F. 2008. Complexity in biology: exceeding the limits of reductionism and determinism using complexity theory. Embo Reports 9(1):10-14. http://dx.doi.org/10.1038/ sj.embor. 7401147

Mitchell, S. 2009. Unsimple truths. Science, complexity, and policy. University of Chicago Press, Chicago, Illinois, USA. http://dx.doi.org/10.7208/chicago/9780226532653.001.0001

Morin, E. 2008. On complexity. Cresskill, Hampton, USA.

Nel, J. L., K. M. Murray, A. M. Maherry, C. P. Peterson, D. J. Roux, A. Driver, L. Hill, H. Van Deventer, N. Funke, E. Swartz, L. B. Smith-Adao, N. Mbona, L. Downsborough, and S. Nienaber. 2011. Technical report: National Freshwater Ecosystem Priority Areas (NFEPA) project. Report to the Water Research Commission, CSIR, WRC, SANParks, SANBI, SAIAB, Monash-South Africa, WRC Report No. 1801/2/11. [online] URL: http://bgis.sanbi.org/nfepa/project. asp 
Norberg, J., and G. Cumming. 2008. Complexity theory for a sustainable future. Columbia University Press, New York, New York, USA.

Pohl, C., and G. H. Hadorn. 2007. Principles for designing transdisciplinary research: proposed by the Swiss Academy of Arts and Sciences. Oekom, Munich, Germany.

Popper, K. 1963. Conjectures and refutations: the growth of scientific knowledge. Routledge, London, UK.

Preiser, R., and P. Cilliers. 2010. Unpacking the ethics of complexity: concluding reflections. Pages 265-287 in P. Cilliers, and R. Preiser, R., editors. 2010. Complexity, difference and identity. An ethical perspective. Springer, Dordrecht, The Netherlands. http://dx.doi.org/10.1007/978-90-481-9187-1_13

Preiser, R. 2012. The problem of complexity. Re-thinking the role of critique. Dissertation. Department of Philosophy, Stellenbosch University, Stellenbosch, South Africa.

Prigogine, I. 1997. The end of certainty. The Free Press, New York, New York, USA.

Resilience Alliance. 2010. Assessing resilience in socialecological systems: workbook for practitioners. Version 2.0. [online] URL: http://www.resalliance.org/3871.php

Roux, D. J., J. L. Nel, H. M. Mackay, and P. Ashton. 2006. Discussion paper on cross-sector policy objectives for conserving South Africa's inland water biodiversity. Report No TT 276/06. South African Water Research Commission, Pretoria, South Africa.

South African National Biodiversity Institute (SANBI). 2008. National freshwater ecosystem priority areas. SANBI, Claremont, South Africa.

Ulanowicz, R. E. 2009. A third window: natural life beyond Newton and Darwin. Templeton Foundation, West Conshohocken, Philadelphia, USA.

Urry, J. 2005. The complexity turn. Theory, Culture and Society 22(5):1-14. http://dx.doi.org/10.1177/0263276405057188

Walker, B., S. Carpenter, J. Anderies, N. Abel, G. Cumming, M. Janssen, L. Lebel, J. Norberg, G. D. Peterson, and R. Pritchard. 2002. Resilience management in social-ecological systems: a working hypothesis for a participatory approach. Conservation Ecology 6(1):14.

Wilber, K. 2001. A brief history of everything. Gateway, Dublin, Ireland.

Will, C. 2008. An approach to tracking whether change is sustainable in complex social-ecological Systems. Pages 569597 in M. Burns, and A. Weaver, editors, Exploring sustainability science: a southern African perspective. Sun Press, Stellenbosch, South Africa.
Woermann, M., and P. Cilliers. 2012. The ethics of complexity and the complexity of ethics. South African Journal of Philosophy 31(1):403-419. http://dx.doi.org/10.1007/978-94-007-5131-6_2 